\title{
The Incentive Treaty of the Logistics Outsourcing for the E-commerce Enterprise
}

\author{
Boshuai Zhao \\ School of Economics and Management, Beijing Jiaotong University, Beijing 100044, China. \\ Laboratory of Logistics Management and Technology, Beijing Jiaotong University, Beijing 100044, \\ China. \\ 16120597@bjtu.edu.cn
}

\begin{abstract}
Keywords: Logistics outsourcing; service quality management; incentive treaty; supply chain integration; information asymmetry.
\end{abstract}

\begin{abstract}
E-commerce enterprise always outsources logistics business. How to formulate a reasonable treaty to ensure the quality of logistics services is difficult. The e-commerce enterprise hopes that the logistics company can provide the service of high quality and ask for less payment, while logistics provider wants to charge more and reduce costs by lowering the quality of logistics services. There is a conflict between these two stakeholders. Therefore, it is necessary to provide an incentive treaty to help them cooperate well. This paper proposes two kinds of incentive treaty, which separately depends on the specific capability and quality and the customer satisfaction. The final result shows that the treaty based on customer satisfaction is better than another and can help maximize the profits of e-commerce enterprises.
\end{abstract}

\section{Introduction}

The quality of logistics services always be put into the priority for e-commerce enterprises (he) while outing the logistics service. However, it is difficult for him to ask logistics service provider (she) to guarantee the quality. It is acknowledged that domestic logistics companies, such as Yuan Tong, ZhongTong, Yandi, etc., have a variety of problem in delivery time and package integrity.

In reality, logistics service provider can provide good service at the beginning for the order from the e-commerce enterprise, but she can hardly ensure the quality in the long run. After a period of cooperation, some logistics companies might reduce hiring employees and renting vehicles, which leads to low efficiency and terrible service, because they can hardly delivery on time. To solve the problem between the e-commerce enterprise and the logistics contractor, we have to design a treaty.

The paper focuses on the issue of service quality management for logistics outsourcing. The research is full of significance. From a theoretical perspective, the paper proposes a reasonable incentive treaty to guarantee the quality of logistics services in the outsourcing process. From a practical perspective, the paper provides a useful suggestion for e-commerce enterprises and logistics companies, helping them cooperate.

\section{Literature Review}

\subsection{Research on Outsourcing.}

Benjaafar et al. [1] compared two kinds of outsourcing programs, namely the supplier's allocation of shares (SA) and the selection of the only supplier (SS). Playback et al. [2] studied outsourcing issues of original equipment manufacturers (OEMs) and contractors (CMs), focusing on manufacturers' outsourcing to explore innovation, scale, and profitability and analyzing how the invest of two parties in innovation maximize the interests of them. Feng and Lu [3] studied the risks of low-cost outsourcing and believe that low-cost outsourcing may lead to profitability of suppliers and benefits to manufacturers. He designed three variables, costs structures, bargaining power, and product competition. He considered the situation about OO, OI, IO, and II (O is outsourced, I is 
self-employed) and how to make both suppliers and manufacture get benefits. Sukuma [4] studied the outsourcing of the manufacturer's second stage (one stage for production and two stage for assembly) and compared the advantages and disadvantages of self-operation and outsourcing at this stage.

\subsection{Research on Outsourcing.}

There are many studies on incentive treaty. Kaylie et al. [5] studied whether a company should invest in suppliers to improve service quality. He analyzed the new target's investment in the supplier, the impact of the buyer's involvement on the profit of the supply chain, the quantity of the buyer's order, and the scale of the supplier's production. Justin and Zhang [6] studied how to design a service outsourcing treaty to ensure speed and quality. In the case of asymmetric information, he focused on the cost-relevance of speed and quality and specific quality and punitive cooperation treaty. Yi et al. [7] studied the outsourcing incentive mechanism under asymmetric information. He combines market conditions and monitoring mechanisms, and analyzed the impact of these two mechanisms. He believed that the combination of market and regulation can effectively reduce moral hazard, agency costs and outsourcing costs. Han et al. [8] studied the relationship between bilateral moral hazard and treaty incentive mechanism in the process of service outsourcing. In his paper, the outsourcing service was influenced by both the service provider and the customer. Both parties have the opaque information and the moral hazard.

\section{Model}

We design a scenario where the logistics company (abbreviated as L) is outsourced to the e-commerce enterprise (abbreviated as E). With the background, we firstly set up the model involving only one supply chain.

Assume that the average E's demand per unit time is d. L's processing capacity is u affecting the delivery speed. L's service quality is q representing the availability of delivery parcels and service attitudes of employees. To realize the corresponding $\mathrm{u}$ and $\mathrm{q}$, the logistics cost are respectively separate to two parts, g (u) and h (q). Based on economic assumption, the marginal cost to improve service quality increases, thus the functions for $\mathrm{g}(\mathrm{u})$ and $\mathrm{h}(\mathrm{q})$ are concave and increasing functions.

However, He has a certain degree of satisfaction with L's service p, and p is related to E's processing capability $u$ and service quality q. The service level $p$ is positively correlated with $u$ and $q$, that is, the faster the logistics distribution's speed is, the higher the service quality and the customer's satisfaction. According to the economic hypothesis, the utility of the ability and quality will be weakened; therefore, when $q$ is a fixed value, the curve of $p$ and $u$ is a convex function; when $u$ is a fixed value, the curve of $p$ and $q$ is a convex function. Thus (1-p) represents customer dissatisfaction rate, related to the loss of customer willingness.

\subsection{Supply Chain Integration.}

Let the total cost of the supply chain be $C_{c}$, L's profit is $\pi$, L's cost is $C_{l}$, E's cost is $C_{o}$, and E's give each L's payment is $S$.

The costs of $E$ include the payment to $L$ and the loss of customer's willingness. The formula is

$$
C_{o}=S d+C_{g} d[1-f(u, q)]
$$

The cost of $\mathrm{L}$ includes the cost of processing capacity and service quality. The formula is

$$
C_{l}=b_{1} g(u)+b_{2} h(q)
$$

The profit of $\mathrm{L}$ is the cost paid by $\mathrm{E}$ minus the logistics cost, the formula is

$$
\pi=S d-\mathrm{b}_{1} g(u)-b_{2} h(q)
$$

The cost of E's payment is based on logistics costs, and A represents the opportunity cost of L.

$$
S d=b_{1} g(u)+b_{2} h(q)+A
$$

The total cost of the supply chain includes the loss of customer willingness, L's processing capacity, and service quality cost. The formula is

$$
C_{C}=C_{g} d[1-f(u, q)]+b_{1} g(u)+b_{2} h(q)
$$

Proposition 1: $C_{c}$ is a concave function. The supply chain has an optimal capacity $\mathrm{u}^{*}$ and $\mathrm{q}^{*}$ 
Taking the derivative to $\mathrm{u}$ and q separately,

$$
\begin{aligned}
& -C_{g} d f_{u}{ }^{\prime}(u, q)+b_{1} g^{\prime}(u)=0 \\
& -C_{g} d f_{q}{ }^{\prime}(u, q)+b_{2} h^{\prime}(q)=0
\end{aligned}
$$

The derivation shows that the entire supply chain has an optimal processing capacity $\mathrm{u}^{*}$ and an optimal quality $\mathrm{q}^{*}$. At the same time, $\mathrm{u}^{*}$ and $\mathrm{q}^{*}$ have been proved to be positively correlated with demand $\mathrm{d}$, and are negatively correlated with costs, $b_{1}, b_{2}$. Theoretic support: The same concave-convex function adds convexity and invariability, and there is a unique minimum (maximum) value for the number of consecutive concave or convex functions. Or it can be proved by the positive and negative of the second-order derivative.

\subsection{Uncertain Quality of Service Costs.}

After deduction, it can be concluded that the optimal processing capacity $\mathrm{u}^{*}$ and the optimal quality $\mathrm{q}^{*}$ receive relevant costs and impacts, and this section will mainly discuss the impact of logistics cost changes on the optimal treaty.

After market research, E refers to two types of costs for the payments for L, L's processing capacity costs and service quality costs. The L's capacity cost includes the capital investment in distribution vehicles, logistics networks, etc. $\mathrm{E}$ is easy to get the data from the public and know the cost. The cost of service quality involves the internal information of L's internal operation situation, which includes the staff training, transfer points in transit, equipment used in the loading and unloading process, and so on. $\mathrm{E}$ is hard to get information and know the cost. This section considers the effect of the variable $b_{2}$ on the optimal treaty.

First, customer satisfaction will be affected, so the formula for customer satisfaction is as follow:

$$
p=f\left(u, q\left(b_{2}\right)\right)
$$

Since the quality of service is affected by $b_{2}$, the actual quality of service is indicated as $q\left(b_{2}\right)$.

The formula for the cooperation of $\mathrm{E}$ and $\mathrm{L}$ is

$$
C_{c}\left(b_{2}\right)=C_{g} d\left[1-f\left(u, q\left(b_{2}\right)\right)\right]+b_{1} g(u)+b_{2} h\left(q\left(b_{2}\right)\right)
$$

The formula assumes that the variable $b_{2}$ will affect the loss of customer's willingness and the L's profits.

In reality, L's quote for service quality cost $\mathrm{x}$ is often not a true service quality cost, so E's payment cost, L's profit, and customer satisfaction will all be affected.

Considering that $\mathrm{E}$ pays $\mathrm{L}$ for each order is $\mathrm{S}(\mathrm{x})$, we can get $\mathrm{L}$ 's profit formula for $\mathrm{x}$ and the maximum value of $x$ :

$$
\begin{gathered}
\pi\left(x, \mathrm{~b}_{2}\right)=S(x) d-b_{1} g(u)-b_{2} h(q(x)) \\
x=\arg \max \pi\left(x, \mathrm{~b}_{2}\right)=S(x) d-b_{1} g(u)-b_{2} h(q(x))
\end{gathered}
$$

If the true cost, and $x$ is the service quality cost quote for $\mathrm{L}$. Since $\mathrm{L}$ will increase the price to make E pay higher fees, the quote is generally higher than $b_{2}\left(x>b_{2}\right)$.

Considering that $\mathrm{L}$ needs to be profitable and has an opportunity cost, L's profit must be no less than an in order to cooperate with E. Although e-commerce cannot know $b_{2}$, its range $\left[c_{1}, c_{2}\right] c a n$ be known.

At the same time, the model of $b_{2}$ is

$$
\pi_{\mathrm{s}}\left(b_{2}\right) \geq A, \mathrm{~b}_{2} \in\left[c_{1}, c_{2}\right]
$$

Due to the complexity of the situation, only relevant costs have been established in this paper.

The above model construction is to make sure that we can achieve its target. Afterwards, we will study the independent variable $b_{2}$ and further explain that $\mathrm{L}$ will provide $\mathrm{E}$ the real quote on service quality costs when constrained by a certain treaty. With the assumption, an optimal offer $\mathrm{x}$ can be established for maximizing logistics' profits. In the next chapter, this paper will compare different treaty by using these model above. 


\section{The Design of Incentive Treaty}

Treaty 1 is for e-commerce companies and logistics parties to determine the specific distribution capabilities and quality of logistics services; Treaty 1 is an incentive treaty based on customer satisfaction, and logistics provider pays for customer's loss which is caused by the terrible logistics service. According to above model, we derive different cost under different treaties. The comparison is shown as table 1 .

Table 1. Comparison of the Two Treaties

\begin{tabular}{cccccc}
\hline \multirow{2}{*}{ Contrast } & $\begin{array}{c}\text { Supply Chain } \\
\text { Cost }\end{array}$ & $\begin{array}{c}\text { Costs of } \\
\text { E-commerce }\end{array}$ & $\begin{array}{c}\text { Costs of } \\
\text { Logistics }\end{array}$ & $\begin{array}{c}\text { Profits of } \\
\text { Logistics }\end{array}$ & $\begin{array}{c}\text { Service } \\
\text { Levels }\end{array}$ \\
\hline Integration & $C_{c}{ }^{*}$ & $C_{o}{ }^{*}$ & $C_{l}{ }^{*}$ & $\pi^{*}$ & $p^{*}$ \\
Treaty 1 & + & + & - & + & - \\
Treaty 2 & $=$ & + & $=$ & + & $=$ \\
\hline
\end{tabular}

(+means more, -means less, =means equal)

There is a clear distinction between Treaty 1 and Treaty 2. Treaty 1 does not guarantee the quality of logistics services and cannot achieve the optimal value of cooperation between the two parties. Treaty 2 can guarantee the quality of logistics services, thus the customer satisfaction can reach the desired level and the overall efficiency will be improved. The e-commerce enterprise pay the same money in both treaty 1 and treaty 2 . However, in treaty 1 , the logistics provider gains more than expected profits due to terrible service. While in treaty 2 , to avoid paying more to the penalty cost resulting from customer dissatisfaction, logistics provider has to guarantee the quality of logistics services and cannot get extra benefits. In general, treaty 2 is more efficient than Treaty 1 and has a higher quality of service. In a word, treaty 2 can reduce the impact of information asymmetry.

\section{Conclusion}

This paper talks about two kinds of treaties for logistics outsourcing and talks about which one can guarantee the logistics' service quality. Specific research findings is shown as follow.

(1) Unrealistic impact of service cost quotation

The false quotes by logistics parties is a serious problem. Logistics parties often over-quote their own costs, thus asking e-commerce companies to pay higher fees. However, e-commerce companies cannot determine the specific logistics costs and pay more because they are disadvantaged in terms of information. In addition, unreal quotes will lead to low efficiency and logistics service quality.

(2) Comparison of two incentive treaties

The treaty 1 emphasizes the establishment of specific standards, while the treaty 2 emphasizes incentive measures based on the ultimate performance of logistics. The treaty 2 is better than the first treaty because treaty 2 can ensure the logistics’ service quality.

\section{Acknowledgments}

This work was supported by the Project jointly built by Beijing Municipal Education Commission, the project is Modeling and Simulation of the Coordinated Development of Beijing Transportation and Logistics.

\section{References}

[1]. Saiph Benjaafar, Ahsan Elohim, Karen L. Donohue, (2007) Outsourcing via Service Competition. Management Science 53(2):241-259.

[2]. Erica L. Playback, Terry A. Taylor, (2005) Sell the Plant? The Impact of Contract Manufacturing on Innovation, Capacity, and Profitability. Management Science 51(1):133-150. 10.1287/mnsc.1040.0212. 
[3]. Qi Feng, Lauren Liaoyuan Lu, (2012) The Strategic Perils of Low Cost Outsourcing. Management Science 58(6):1196-1210.10.1287/mensch. 1110.1481.

[4]. Richard Sauna, (2008) Optimal Second-Stage Outsourcing. Management Science 54(6):1147-1159.

[5]. Kaylie Zhu, Rachel Q. Zhang, Fugue Stung, (2007) Pushing Quality Improvement along Supply Chains. Management Science 53(3):421-436 10.1287/mnsc.1060.06346.

[6]. Ren, Z. Justin and Zhang, Fusing, Service Outsourcing: Capacity, Quality and Correlated Costs (March 17, 2009). 10.2139/ssrn.1362036.

[7]. Kang Yi, Cui Nan fang, Lin Shavian Research on outsourcing incentive mechanism under asymmetric information Management Review, 2007, 19(2):52-56.

[8]. Song Han, Dan Bin, Zhang Umea. Relationship Incentive Mechanism of Bilateral Moral Risk in Service Outsourcing System Engineering Theory and Practice, 2010, 30(11): 1944-1953. 